\title{
Action Research: An Essential Approach for Constructing the Development of Sustainable Urban Agricultural Systems
}

\author{
Antonia D. Bousbaine ${ }^{1}$ and Christopher R. Bryant ${ }^{2,3, *}$ \\ ${ }^{1}$ Department of Geography, University of Liège, Liège, Belgium \\ 2 School of Environmental Design and Rural Development, University of Guelph, Guelph, Canada \\ ${ }^{3}$ Department of Geography, University of Montréal, Montréal, Canada. \\ * Corresponding author: E-Mail: christopher.robin.bryant@gmail.com; Tel.: +1 5198461361
}

Submitted: 28 January 2016 | In revised form: 7 April 2016 | Accepted: 10 April 2016 |

Published: 24 May 2016

\begin{abstract}
How can research contribute more directly to promoting and leading to sustainable solutions and projects? This article suggests that one of the most important research approaches capable of achieving this is the Action Research approach. This involves the researcher taking on a number of roles when working with other actors (e.g. citizens, farmers, local elected officials, citizen associations, government representatives... with the specific set of actors depending upon the nature of the subject being investigated and for which solutions are sought). The roles that the researcher can play involve providing appropriate information to the other actors, providing counseling to them, organizing and animating meetings with the actors, and accompanying the whole process involving all the actors. These roles are essentially played out by the researcher when the other actors request the researcher to assume whichever roles they consider to be significant. The fundamental notion is that through this process the actors appropriate the sustainable solutions as their own, and the researcher helps them achieve this. This article is based on: a) a synthesis of pertinent research using the Action Research approach (specifically in relation to sustainable agricultural systems in periurban territories), and b) specific research undertaken by the two co-authors of the article, all in the context of periurban agricultural systems during the last 8 years, as well as on some of their publications. The necessary characteristics of Action Research and the researchers involved are identified, namely: a) patience; b) an emphasis on process; and c) an emphasis on participation on the part of multiple actors.
\end{abstract}

Keywords: Action Research; periurban agricultural systems; roles of researchers; sustainable development solutions

\section{Introduction}

Increasingly, the notion of so-called 'sustainable' agricultural systems raises many questions for many actors both in government and in the research community. With increasing urbanization, urban spaces penetrate more and more into what remains of their surrounding rural areas, and this territorial fringe, which has often been called a hybrid space, has become the focus of much attention in recent years [1]. With the introduction of the concept of sustainable development, a shift has become necessary in the food supply systems for cities and therefore ultimately in the modes of 'production'. Since the end of WW2, state authorities have largely focused on industrial agriculture de- 
spite its share of negative externalities for the environment and public health; today more than ever, this agriculture which occupies the smallest spaces within agglomerations and remains the largest land user on the edges of cities, naturally leads us to rethink the agricultural reality. In relation to this, both public and private actors have a duty to be resourceful in order to highlight the fact that agriculture adjacent to and within urban agglomerations remains vital for certain population segments in both developed and developing countries [2]. However, much of the research that has been emerging on this issue does not put enough emphasis on Action Research, an approach that has come directly from North America and in many respects has given rise to very relevant results.

This urban (including periurban) agriculture (UPA) has to face many challenges; the researcher can in many cases contribute to the emergence of solutions, while at the same time remaining open and willing to meet the demands of the actors involved. The researcher's roles remain essential in this Action Research approach-as informant, advisor and in accompanying the actors in their construction of pertinent and, today, sustainable projects.

This article is focused on the importance of Action Research and the challenges presented by urban and periurban agriculture (UPA), particularly in relation to the new production systems introduced by actors practicing this UPA. We argue that Action Research can play an important role in developing more sustainable forms of UPA. Our examples from France, Canada and more recently from the Pays de Herve, Belgium, demonstrate some of the most important aspects of an Action Research approach and especially emphasize the importance of the 'researcher' in this process.

\section{What is Action Research?}

Action Research is a scientific approach that was not born spontaneously; its beginnings have been attributed to social scientists, from the 19th century and the first quarter of the 20th century [3]. The use of the term by Kurt Lewin in 1933 ultimately defined the fundamental concept [4]. Action Research highlights the importance of a methodological approach in which the "individual" is central to success both in terms of the individual researcher and the dynamics of the relationships in which the individual researcher finds him or herself.

Thus, this creates an interaction between the researcher and the object of the research; namely, the social group at the center of the research. There has since been a proliferation of work using the Action Research approach, especially after the Second World War, and it is occupying an increasingly significant place in the scientific world particularly because of the interest in finding practical solutions to various issues.

What then really is Action Research?

The researcher's attention is focused on the object of the research, involving the systematic collection of observable and verifiable data, in order to describe, explain, anticipate and plan future events. Research and action are thus intimately connected within the same activity, taking as a reference point the group of actors (individuals and collective actors such as associations, municipalities...) on which the research is focused.

According to Lewin, Action Research is a type of scientific approach that can be adapted to everyday life, and the researcher must therefore be fully involved in the projects aimed at transforming the social reality [5]. The researcher must be particularly careful in relation to how his or her involvement and influence in the phenomena being studied are taken into consideration. Finally, the ethical dimension of the researcher is highlighted in this research approach, and once defined it must be maintained.

Finally, and to summarize, Action Research characteristically involves different actors, which in the context of this article includes farmers, their families and associations but also political actors, professionals and citizens, all of whom end up working together to create agricultures and agricultural territories that are sustainable.

\section{What Are The Challenges That Urban And Periurban Agriculture (UPA) Must Face?}

Increasingly agriculture is losing ground against the relentless advance of the city, and the issue of the conservation of farmland is one of the first challenges that has to be resolved. In Canada, legislation has been put in place to preserve agricultural land (1973 in British Columbia and 1977 in Quebec as well as strong guidelines for municipalities and regions in Ontario from 1978 onwards); in the United States, in the 1960s, considerable efforts were also put in place to conserve farmland in several States $[6,7]$.

In France, the inclusion of UPA has played an important role in territorial planning and development policies since the mid-1970s, and a more formal approach began to be integrated into these policies after 2000, both at national and regional levels [8]. In Wallonia, it was only in March 2014, that the Code wallon de l'agriculture was put in place; the objectives of this Code appear to be very pertinent but for the moment real actions have yet to be undertaken.

Overall, however, the issue of dealing with UPA has become widely recognized and integrated into the thinking of public authorities, largely because of the multitude of functions that these agricultures support for the benefit of society, including food production, leisure, environmental (ecosystem services) and residential functions. These functions can often be in conflict with each other and give rise to conflicts that several governments have attempted to control and reduce. Each function can be associated with different actors each with their own perspectives and interests to defend. Nevertheless, it is the agricultural production function which suffers the brunt of the advancing urban area, and despite attempts to curb these losses, it is clear that losses of farmland continue even where there is strong legislation to conserve farmland resources. And when farmland is lost so are the many other functions that 
farmland and farming activities support.

The results remain positive in Canada and France, but in Belgium, especially in Wallonia, where despite the Walloon Code and the Sector Plans which 'determine' land uses on the ground, we have to recognize that losses of farmland are still significant, amounting to up to $80 \%$ in some municipalities over a relatively short period of time [9] and are still continuing. The initial results of research on the municipalities in the Pays de Herve follow along these lines and in 30 years (1980 to 2010), this part of the Walloon region has shown a $70.4 \%$ drop in farmland area $[10,11]$.

One of the major challenges facing UPA is to be able to ensure its sustainability, and not just through the type of agricultural land conservation legislation that exists in several Canadian provinces and the other efforts made in France more recently.

Some useful results can be identified in certain French regions, just as in Canada, but enormous efforts are still required in Wallonia. Another challenge concerns what has been happening to agricultural activity in France, where over 200 farms disappear each week [12] and overall in Wallonia, where $36 \%$ of the farmers do not know whether they will have a successor. In relation to this, Action Research can become part of the solution and contribute to the development of agricultural development plans aimed at the development of sustainable agricultural systems including the creation of improved incomes.

This situation really seems more than worrying and challenging, and it raises the question of the relationship between the city and its agricultures (UPA). This in turn requires a much better understanding of the relationship between citizens and farming (and food production generally including urban gardens of different types) in and around cities, and of the expectations of citizens. Indeed, more and more farmers are questioning the challenges related to this cohabitation between the farming population and non-farm population, such as how to respond to new social expectations, related on the one hand to environmental issues and on the other hand to the mistrust born of the various health crises that have shaken the agricultural world. Developing sustainable agricultural areas and farm activities requires much more than land use planning even though appropriate land use planning structures and regulations are important. The construction of agricultural development plans is what is needed to complement land use planning, as has been happening in Quebec, Canada, since 2008.

Periurban agriculture has had to contend with continued urban expansion, including urban sprawl in many countries despite land use planning. Periurban farms, as elsewhere, also have to cope with difficulties in their functioning, partly related to agricultural machinery becoming larger and larger making it increasingly more difficult to maintain their farm operations (i.e. the globally competitive and capitalist form of agriculture that has become so important in many Western countries) because of traffic circulation problems in these territories. Furthermore, the isolation, splitting up and fragmentation of farms are all challenges that have to be taken into consideration on behalf of and by these farmers. Furthermore, in some jurisdictions such as Ontario, Canada, agricultural land use planning has favored the large scale productivist and capitalist system of agriculture in areas where the property parcels are very large; land use planning has tended to refuse breaking such property parcels into smaller parcels because of earlier concerns over ex-urbanization processes. However, this approach makes it more difficult for some types of emerging farms (such as small scale organic farms and small farms that use limited agricultural machinery) to become established in such areas despite an increasing market for their produce; and land rental is limited because of the lack of legislation permitting secure farmland tenure in such areas.

Added to this is an important lack of knowledge of the farming profession by citizens who often continue to see agriculture as being made up of the fermes d'antan, and who remain very demanding in terms of services provided to them by farmers. Farmers often hope to find solutions to their problems in these periurban areas through infrastructure development, which in reality is more often detrimental to agriculture.

All of this is reinforced by the lack of attractiveness of the farming profession, which creates problems in terms of manpower, as well as has already been mentioned the commonly held negative image of this profession.

In addition to these challenges are added questions related to energy, which will become pressing in the very near futurehow to deal with the energy crisis, what are the alternatives to replace fossil fuels, and how can agriculture respond?

Furthermore, farming is also facing the inevitable consequences in the European Union that the Common Agricultural Policy has created over a long period of time of always trying to encourage farmers to produce more involving more input use that is harmful to the environment, all of which has led to a reorganization of agricultural production systems that have generated many negative externalities: various types of pollution, soil erosion and increased water use (agriculture is a major consumer of water). The ecological impacts remain a challenge to be met around the world. Many of these challenges are reflected in the very concepts of sustainable development-what are the appropriate solutions from the social, economic and environmental perspectives?

Finally, one of the major challenges affecting the planet is that of food security: how to feed 9 billion people by 2050 [13] while putting in place a so-called 'sustainable' agriculture or agricultures? UPA has an unquestionably significant role to play in improving food security in major urban and metropolitan areas partly because of the very high quality of farmland resources around many cities.

\section{How Can Action Research Help Better Understand this UPA? What Is the Role of the Researcher?}

The Action Research approach remains avant-gardist in empirical studies, although in the last ten years more researchers have adopted the approach. 
This methodology goes far beyond mere traditional research, because the researcher takes on a very specific set of roles and contributes significantly to the advancement of action in the field. Action Research is NOT about a researcher simply collecting data, analyzing it and presenting reports (and scientific publications). The research becomes part of a process involving many other actors and in no way should the researcher control that process. The researcher essentially assumes the following roles to different degrees depending on the circumstances of the project:

- The researcher becomes a provider of information of the broadest range possible, the content of which must be fully understood and appropriated by all the stakeholders involved (public authorities, private citizens, and especially in our present context, farmers and their families...).

- The researcher must also accompany the farmers and other actors in the development, for example, of an agricultural development plan in a municipality in which all actors with legitimate interests who wish to be involved should be involved and participate in meetings that the researcher will organize or help to organize.

- The researcher will also organize meetings such as 'focus groups' with groups of farmers and other stakeholders, with elected officials being particularly important, as we shall see developed in the examples, including that of Christophe Soulard and his team of researchers in the Montpellier Agglomeration.

- The researcher must also really take into account without any prejudice of the legitimate interests of each segment of the populations concerned and involved in and affected by the project. The researcher must also be prepared to ensure that each actor is aware of the importance of his or her involvement over the long term in the proposed solutions.

- The researcher must also be prepared to provide counseling and if necessary advice on bringing in a mediator if no solution appears to be emerging.

The researcher helps participants, in the present domain especially the farmers but also other actors, to better appropriate the multiple functions of agriculture that exist in periurban areas, their importance in the food supply of cities and their role in establishing the territories' long term sustainability in relation to the farmland and agricultural production systems. This means ensuring that the actors involved really understand the importance of maintaining these strategic areas in order to achieve food security.

The role of the researcher and especially his or her personality remains fundamental in Action Research methodology. The researcher must be prepared to listen to all the actors, and to guide them and especially to demonstrate continuously the value of their involvement. The researcher's personal commitment and level of involvement are a 'guarantee' of success in constructing and managing Action Research.

Nevertheless, it is not always easy for the researcher to get the message across; in our case both to farmers, who often maintain their preconceptions, and to the other actors who also often have their own preconceptions. Above all, it requires that the demands of the other actors are well known. The objectives and solutions that are developed as well as the various actions need to be developed by all actors and the researcher can contribute by clearly helping them be defined and contributing to their modification as the process unfolds. The researcher must carry out his or her roles and meet the demands of the people involved. This is clearly not at all like the traditional research roles involving the analysis of different types of data and the preparation of reports, scientific publications and communications: all of these are possible through Action Research, but generally they take more time and necessitate much patience on the part of the researcher.

Continuous support is essential throughout the process, since solutions are always emerging; but it is also the responsibility of the farmers and other stakeholders to be involved, because the probability of success is quite real as long as the actors give their full support. Besides this support, which is provided continuously in group meetings, the researcher's presence on the ground is also essential, both for the farmers and other stakeholders. Insofar as statistical analyses alone do not necessarily reflect the reality, 'cross-checking' is needed to better "understand" the reality and therefore to move to action accordingly. Finally, some special requirements are needed on the part of the researcher, namely the three 'Ps' of Sustainable Development, i.e. Process, Patience and Participation:

- Process: This is extremely important because Action Research involves the researcher taking on the responsibility of involving all stakeholders, both farmers and other actors in the territory (politicians and citizen groups as well as others). The ultimate goal is that each person appropriates the importance of the "multifunctionality" of agricultural land (and farm activities) and their role in environmental issues. To achieve this, initially the researcher can organize discussion groups, which allow the emphasis to be placed on the "knowledge" of each person; note that a whole world often separates farmers from urban citizens, who because they do not know the farmers for the most part, are not able to appreciate how agriculture has become an irreplaceable actor in the renewed city [14]. Moreover, in many cases, in meetings we highlighted the lack of knowledge of the negative externalities of farming by the farmers themselves. Thus, it is up to the researcher to provide them with the appropriate elements so that they can fully appreciate these negative externalities.

- Patience: As recently emphasized by Christophe Soulard [15], Action Research necessitates undeniable qualities in the researcher, especially patience; any researcher must be able to carry out his or her research but above all else from a sustainable development perspective must be able to move the whole process towards possible sustainable solutions. 
By involving all stakeholders, the researcher through the Action Research approach suggested in this text moves towards a constructive and sustainable output with all the other actors, particularly with the purpose of achieving sustainable farmland and farm activities through UPA. It is the other actors who must play a major role in constructing these solutions and must therefore appropriate the ownership of these solutions. So investment of time, listening and engagement are the key qualities inherent to the researcher in the construction of positive results through Action Research, and this is achieved without imposing his or her own ideas and purposes, which would be counterproductive.

- Participation: Without participation, there is no Action Research, of course, and above all, all actors regardless of their socio-economic level are essential for any progress in the process in which the researcher may have had a significant role in starting. All those with an interest in a development plan for agriculture and spatial planning generally need to be invited, if they wish to participate in an 'active' manner. The aim is to bring together stakeholders to develop viable and sustainable solutions for themselves, their families, as well as for future generations (which forms a major objective in the definition of sustainable development).

The co-construction of projects is an efficient approach to establish the parameters to develop sustainable territories. Farming in and adjacent to the city is at the forefront of the construction of territories, as many studies have amply demonstrated.

Nonetheless, each territory has its own specificities and Action Research is not a miracle 'recipe' that can be applied in any territory in the same time frame or in the same way. The specificities of each territory can vary substantially, of course, and this is why the researcher must take account of any given territory's own specificities. Above all else, especially, nothing is set in advance, and profound questioning can take place early on in the process, and therefore the researcher may often find it necessary to contribute to reorienting the Action Research process.

\section{Towards Which Forms of More 'Sustainable'} Farming Systems Should We Move, and How Can We Help Stakeholders Better Understand this Question?

The hybrid space that constitutes periurban territories is constantly evolving; in addition to the many functions that are developing, the dominant activity from a spatial point of view remains agriculture, except where major industrial parks have been developed. The researcher who decides to implement an Action Research process can contribute significantly to the emergence of agricultural plans and projects in these hybrid spaces.

Urban and periurban agriculture has been quite exten- sively integrated into public policies in both France and Canada, but is still struggling to break through in Wallonia. The organization of group meetings between different stakeholders, especially farmers, can contribute to the coconstruction of projects and plans to create more sustainable agricultures. Some researchers have focused attention on agri-urban projects $[16,17]$ and others on projects in more periurban areas [18]. In all situations, it is only by meeting people that the researcher will be able to better explain the Action Research approach and, more importantly, to understand the expectations of each actor.

The importance of the concept of sustainable development, and all the media coverage of the harmful effects of different types of development on the environment and the urgency of preserving the environment, has helped researchers to give their Action Research projects an environmental orientation very quickly. The information and knowledge that researchers have accumulated provides an excellent gateway to involve both farmers, political actors and citizens. The various health crises associated with the agricultural sector and its impact on the health of all citizens, including the negative effects of pesticides, is no longer a secret! If necessary, the researcher can also obtain support from specialized professionals in these domains.

Our examples have highlighted this situation in France, where some researchers have been attempting more and more to implement an Action Research approach and methodology, e.g. by the team led by Christophe Soulard (INRA UMR Innovation in Montpellier) in collaboration with Isabelle Touzard (Mayor Murviel-les-Montpellier and VicePresident of the Metropolis) [15]. The purpose of the researcher and his team has been to support the Metropolis to 'construct a metropolitan agriculture and food policy'. Numerous meetings were held initially to construct an inventory of the agricultural situation with elected officials and then gradually the meetings were extended to include other actors. The awareness of the importance of UPA really helped the construction and implementation of projects for Montpellier.

In the examples developed further below, the researcher's role remains essential, and in many cases, elected officials themselves do not have all the information at their fingertips and especially do not always have the experience to organize focus groups to discuss the unquestionable benefits that agriculture can provide for a territory.

More and more researchers have been focusing their attention on UPA (e.g. [2,19-22], and the authors of this text). All the empirical studies converge on the importance of sustainable UPA, which can not only provide healthy food products but can also create social ties and above all help manage wastes and effluents that will be multiplied by four in cities by 2030 [23] if nothing is done about it, not to mention its contribution to food security.

Modern productivist agriculture has reached very high levels of pollution (e.g. water, air, various types of erosion); researchers who implement an Action Research process 
are naturally often asked at meetings to explain this situation prior to engaging in discussions to reorient these agricultures. Although in the context of periurban agriculture, some authors make no distinction between the different systems of agricultural production, we must recognize that in the structure of the city and its periurban areas not all forms all agricultural production can be considered from a sustainable development perspective. Among the examples encountered in Canada, Bryant and Chahine [18] implemented an Action Research process at the request of a group of farmers in the municipality of Senneville, west of Montreal, who had heard of the Action Research being undertaken at the Université de Montréal; this example gave rise to some very relevant results in terms of establishing long term sustainable agricultures, mostly in terms of organic food production.

In another context-that of Wallonia $\left(16,854 \mathrm{~km}^{2}\right)$ [24], thirty-three times smaller than France - Bousbaine, in the context of preparation of her PhD thesis, has already discussed an outline of Action Research in 2015 in the course of preliminary interviews with 24 farmers and six political actors, by proposing to these respondents the setting up of an Action Research methodology. The importance of these preliminary interviews was undeniable. Indeed, some of the official statistics on agriculture in the territory were in point of fact false, and the results of the meetings were most interesting and led to correcting the erroneous interpretations of the agricultural transformations suggested by official statistics. These preliminary steps were the first steps towards an Action Research process, which is currently being expanded to include the Pays de Herve in 2016. Contacts have already been made at the level of the European Union and with Walloon MPs. The farmers contacted are totally in favor of becoming involved in the discussion groups which will also include citizens. Surveys were also conducted by the NPO (non-profit organization) Au Pays de Herve Futur (In the Future Land of Herve) and certain courses of action have already begun to emerge [24].

The first meetings with a restricted circle of actors are being planned, and it is also necessary to expand the study to include another different study area where concrete actions are being put in place gradually, with a view to achieving more sustainable agricultures environmentally. The WalIoon Code of Agriculture voted in Parliament in March 2014, is oriented in the same direction, so it should be easier for the researcher to involve political leaders.

\section{Conclusion}

The agricultural issue has become the centerpiece for the proper functioning of cities at different scales; both farmers and urban citizens must become fully aware of this situation. The latest events at the gateways to Europe suggest the need to be able to feed more people and emphasize the challenges relating to the urbanization of periurban areas. In addition, of course, there are other major challenges facing these agricultures (UPA), including climate change and the necessary adaptation of agriculture to these changes. All of these other challenges need to be taken into account eventually.

Researchers in Anglo-Saxon countries have been working for some years on the relations between UPA and cities, including more recently through Action Research $[18,25]$, and a number of pertinent results have been observed, especially in terms of increasing the sustainability of the farm systems involved and reinforcing the relationships between farm producers and citizens through different forms of short circuit marketing of food produce.

The meetings and discussions involved in Action Research projects allow the researcher to contribute to the development of a plan that is strategic for the country and the city regions, plans that can be constructed by a wide range of actors, and that can be based on the undeniable interest of UPA and its wide variety of benefits to society. The land issue is an important gateway to discussions, even though some farmers suggest that 'agriculture in the city is not agriculture'. Under these circumstances, it is up to the researcher to remind people that farmers in UPA can contribute substantially to the food supply of cities, while still stressing the need to respect the environment and to develop stronger ties between UPA and the cities. One way this can be achieved is by highlighting for instance the French and Canadian examples, or even the case of the Belgian capital, Brussels, where many community gardens exist and have been encouraged by the Minister of the Environment.

We cannot have researchers in any way deconstruct existing agricultures in a territory, as emphasized by Christophe Soulard [15]; an analysis of the current situation should be undertaken and opportunities discussed that are reconcilable with the agricultures already present even though their farmers may decide to modify their food production systems. In research on the periurban areas around Charleroi [9], few farmers were aware of the opportunities of their spatial proximity to the city, particularly through short food circuits or direct sales. We were then committed to explain to these farmers the interest of maintaining UPA from an environmental perspective and also, of course, the financial benefits generated by their proximity to the city. In addition, the concept of the multi-functionality of agriculture had not been very effectively appropriated by Walloon farmers, and subsequent meetings with officials from the Walloon Federation of Agriculture were very rewarding when this concept was introduced and discussed.

A new process of food governance is looming for both cities and the periurban territories around them, and which is moving towards greater sustainability. Its implementation through Action Research processes focused on a specific territory seems entirely appropriate. Many French examples can support this observation and the researcher can become the link between the various authorities and the other actors (farmers, citizens and various associations and NPOs (not-for-profit organizations). This governance process must: 
- Be articulated to integrate different scales of analysis and action;

- Promote exchanges between the various actors;

- Take into consideration the specificities of the different territories and their inequalities; and

- Support innovative actions that already exist and integrate them with other actions, always keeping in mind the concept of sustainable development.

In this regard, the researcher can contribute to bringing the actors together to transform proposed projects into reality on the ground as in the Pays de Herve where actions are taking place, and as well to support other projects in other territories.

All legitimate interests are thus taken into account by

\section{References}

[1] Bryant CR, Johnston TRR. Agriculture in the City's Countryside. London, UK: Pinter Press; 1992.

[2] Aubry C. Les fonctions alimentaires de l'agriculture urbaine au Nord et au Sud-Diversité et convergences. Bulletin de l'Association de Géographes Français. 2013;90(3):303-317.

[3] Barbier R. La Recherche Action. Paris, France: Editions Economica; 1996.

[4] Lewin K. Action research and minority problems. Journal of Social Issues. 1946;2(4):34-46.

[5] Boisclair M. La Recherche Action. Report prepared for C. Bryant in the context of his research project on the reduction of the vulnerability of periurban agriculture by using an Action Research process and building upon the multi-functionality of periurban agricultural territories. Montreal, Canada: Social Sciences and Humanities Research Council; 2008.

[6] Bryant C, Russwurm L. North American farmland protection strategies in retrospect. GeoJournal. 1982;6(6):501-511.

[7] Bryant C. L'agriculture périurbaine l'économie politique d'un espace innovateur. Cahiers Agricultures. 1997;6(2):125-130.

[8] Les politiques agricoles périurbaines en lle-de-France: état des lieux et analyses de leurs évolutions. Paris, France: Association of Terres en Villes; 2011.

[9] Bousbaine DA. Facteurs d'évolutions et de transformations de l'agriculture dans les communes périurbaines de Charleroi, de 1990 à 2010 [Master Thesis]. Université Libre de Bruxelles, Department of Geography. Brussels, Belgium; 2014.

[10] Lebelle R. Enquêtes croisées agriculteurs-citoyens menée par Pays de Herve-Futur en 2013 : analyses et pistes d'action [Bachelor Thesis]. Haute École Maret, Department of Agronomy. La Reid, Belgium; 2014.

[11] Code Wallon de l'agriculture; 2014. Available from: www.agriculture.wallonne.be.

[12] France Agricole; 2010. Available from: www. the researcher who must have a great deal of patience, be prepared to listen attentively to everyone and be prepared to make a real investment in the project when the actors request it. The purpose remains first, the search for permanent solutions and second, to ensure that the different actors are each satisfied with the process and outcomes. The researcher must make a major commitment to the key players, in our case the farmers, but without putting aside local officials. Finally, the researcher assumes the roles of counselor, of providing advice, and of accompanying the actors in the process, without imposing his or her own views and carrying out these roles only when the other actors ask the researcher to carry out these roles [26].

LaFranceAgricole.fr.

[13] Report 2013. FAO (Food and Agriculture Organisation); 2014.

[14] Rouget N. La ville et son agriculture; Retour vers le futur. Cafégéo de Montpellier. 2014;Available from: http://cafe-geo.net/wp-content/uploads/Affiche2014-15_v2c-1.pdf.

[15] Soulard C, Touzard I. Construire une politique agricole et alimentaire métropolitaine. Proposition méthodologique à partir du cas de Montpellier. In: Colloque International Valenciennes-La Louvière (FranceBelgium) "Nature des villes, nature des champs: Synergies et controverses". Valenciennes, France; 23-25 September 2015.

[16] Bourdeau-Lepage L, Vidal R. Nature urbaine en débat: à quelle demande sociale répond la nature en ville? Déméter. 2013;2013:195-210.

[17] Vidal R. Réconcilier agriculture et paysage. Changer d'agriculture ou changer de regard? In: Cahier Thématiques $\mathrm{n}^{\circ} 11$. Villeneuve-d'Ascq, France: Ecole nationale supérieure d'architecture et de paysage de Lille; 2012. pp. 29-36.

[18] Bryant C, Chahine G. Action research and reducing the vulnerability of peri-urban agriculture: a case study from the Montreal Region. Geographical Research. 2016;54(2):165-175.

[19] Duchemin E, editor. Special Issue: Agriculture urbaine: Aménager et nourrir la ville. Montreal, Canada: Les éditions en environnements VertigO; 2015.

[20] Robineau O, Dugué P, Soulard CT. Les trames vertes des villes africaines au service de l'agriculture urbaine? Pour. 2015;224:257-265.

[21] Poulot M. Agriculture et acteurs agricoles dans les mailles des territoires de gouvernance urbaine: nouvelle agriculture, nouveaux métiers? Espaces et Sociétés. 2014;(3):13-30.

[22] Chiffoleau Y. Circuits courts alimentaires, dynamiques relationnelles et lutte contre l'exclusion en agriculture. Économie Rurale. 2013;(6):88-101.

[23] Smith OB, Moustier P, Mougeot LJA, Fall A. 
Développement durable de l'agriculture urbaine en Afrique francophone. Ottawa, Canada: Centre de Coopération Internationale en Recherche Agronomique (CIRAD) and International Development Research Centre (IDRC); 2004.

[24] Au Pays de Herve Futur (Non Profit Organisation); 2016. Available from: www.aupaysdehervefutur.be.

[25] Bryant CR, Chahine G, Saymard E, Poulot M, Charvet JP, Fleury A, et al. The Direct Contribution of Research to Modifying Spatial Patterns of Local Development: Action Research to Reduce Vulnerabilities and Re-Build Agricultural Activity in the Urban Fringes of Montreal and Paris. In: Proceedings of the $40^{\text {th }}$ Conference of the Mid-Continent Regional Science Association and the $31^{\text {st }}$ Annual Conference of the Canadian Association of Regional Science. Milwaukie, OR, USA; 28-30 May 2009. pp. 67-78.

[26] Bousbaine AD, Bryant CR. The Integration of Action Research and Traditional Field Research to Provide Sustainable Solutions to Maintaining Periurban Agriculture. Geographical Research. 2016;54(2):176-186. 